Jpn. J. Human Genet. 31, 263-271, 1986

\title{
GENETIC POLYMORPHISMS OF COMPLEMENT C6 AND C7 IN TWO CHINESE POPULATIONS
}

\author{
Zhi-min Zeng, ${ }^{1}$ Katsushi ToKunaGa, ${ }^{1}$ Keiichi Oмото, ${ }^{1}$ \\ and Chuanshu Du² \\ ${ }^{1}$ Department of Anthropology, Faculty of Science, The University of Tokyo, \\ Hongo, Bunkyo-ku, Tokyo 113, Japan \\ ${ }^{2}$ Department of Medical Genetics, Sun Yat-sen University of \\ Medical Science, Guangzhou, China
}

\begin{abstract}
Summary Genetic polymorphisms of the complement components C6 and $\mathrm{C} 7$ in two Chinese populations (Beijing and Guangzhou) were investigated, using isoelectric focusing and immunoblotting technique. Three common and four rare allotypes of C6 were observed, and one of the rare allotypes was considered to be a new variant. Ten different patterns of C7 observed were classified into three homozygous and seven heterozygous phenotypes, indicating occurrence of four common and a new variant alleles. The new variants of $\mathrm{C} 6$ and $\mathrm{C} 7$ detected were designated as $\mathrm{C} 6$ $\mathrm{B} 21$ and $\mathrm{C} 76$, respectively. There was no statistically significant difference for $\mathrm{C} 6$ and $\mathrm{C} 7$ allele frequencies between the Beijing and the Guangzhou populations except for $C 7 * 4$. The $C 7 * 4$ frequency was shown to be significantly higher in Beijing than in Guangzhou. No significant positive association between $\mathrm{C} 6$ and $\mathrm{C} 7$ alleles was found.
\end{abstract}

\section{INTRODUCTION}

Genetic variants involving charge differences have been described for more than half of the complement components. Genetic polymorphism of the sixth component of human complement (C6) was first detected by Hobart et al. (1975). Subsequent investigations on $\mathrm{C} 6$ in several populations have shown a high degree of allelic variation particularly among Asian-Pacific populations (Kunstmann et al., 1980; Olving et al., 1980; Ranford et al., 1982; Tokunaga et al., 1983, 1984). However, no study was reported in mainland Chinese up to now.

The close linkage between C6 and C7 loci has been confirmed (Hobart et al., 1978; Tokunaga et al., 1986). A genetic study of structural variants of the seventh component of human complement (C7) was first carried out by Hobart et al. (1978),

Received June 27, 1986; Accepted July 19, 1986 
using polyacrylamide gel isoelectric focusing followed by functional detection. It was reported that the inheritance of the observed patterns of $\mathrm{C} 7$ are determined by three codominant alleles, $C 7 * 1, C 7 * 2$, and $C 7 * 3$, at a single autosomal locus. The investigations of $\mathrm{C} 7$ polymorphism in Japanese have been performed using polyacrylamide gel isoelectric focusing followed by immoblotting techniques, involving electrophoretic transfer (Nakamura et al., 1984a), or press blotting (Tokunaga et al., 1986). No study has been reported on this system in Chinese.

Nakamura et al. (1984a) suggested that the three common allotypes of C7 named $\mathrm{C} 7 \mathrm{~B}, \mathrm{C} 7 \mathrm{M}$, and $\mathrm{C} 7 \mathrm{~A}$ correspond to $\mathrm{C} 71, \mathrm{C} 72$, and $\mathrm{C} 73$ described by Hobart et al. (1978), respectively. However, the third allotype has been found to be identical to the C7 4 by Lachmann and Hobart (see Tokunaga et al., 1986). Recently, Nishimukai and Tamaki (1986) described the new cathodal variant in Japanese, named C7 5, recognized in neuraminidase-treated samples.

The present study is the first report on the polymorphisms of complement C6 and $\mathrm{C} 7$ in China. The $\mathrm{C} 6$ and $\mathrm{C} 7$ polymorphisms were investigated using polyacrylamide gel isoelectric focusing followed by immunoblotting in two populations (Beijing and Guangzhou) of mainland China. The result of an association analysis between $\mathrm{C} 6$ and $\mathrm{C} 7$ alleles was also described.

\section{MATERIALS AND METHODS}

Blood samples were obtained from normal unrelated Chinese (Han nationality) adults. Among these, 155 blood samples were from Beijing and 255 samples were from Guangzhou. The samples were airshipped to Tokyo and then were stored at $-30^{\circ} \mathrm{C}$ prior to examination.

For C6 typing, slab gels $(200 \times 130 \times 0.5 \mathrm{~mm})$ were prepared using $2.8 \mathrm{ml}$ of acrylamide solution $29.1 \%(\mathrm{w} / \mathrm{v}), 2.8 \mathrm{ml}$ of bis-acrylamide solution $0.9 \%(\mathrm{w} / \mathrm{v})$, $0.5 \mathrm{~g}$ taurin, $0.9 \mathrm{ml}$ of Ampholine pH 5-8 (LKB), $10 \mu \mathrm{l}$ of TEMED, and $10 \mathrm{ml}$ of distilled water. The gel was photopolymerized with $0.4 \mathrm{ml}$ of riboflavin solution at room temperature. Isoelectric focusing and immunoblotting were performed according to Tokunaga et al. (1984).

For $\mathrm{C} 7$ typing, the acrylamide gel was prepared in the similar manner as for C6. Plasma samples were treated with $5 \mathrm{U} / \mathrm{ml}$ neuraminidase (Sigma Chemical Co., St. Louis) overnight at room temperature prior to isoelectric focusing. Immunoblotting was carried out in the similar manner as for C6 (Tokunaga et al., 1986). A goat anti-human C7 serum (Cappel Lab. Inc., West Chester) diluted 1:400 with 3\% bovine serum albumin in phosphate-buffered saline (BSA/PBS) was used as the first antibody and a peroxidase-conjugated anti-goat immunoglobulins (Dako Patts a/s, Glostrup, Denmark) diluted 1:1,000 with BSA/PBS was used as the second antiserum.

Association analysis was performed by Chi-square test with Yates' correction. 


\section{RESULTS}

The photograph of the nitrocellulose membrane showing the patterns of the various C6 phenotypes is shown in Fig. 1. At least ten different phenotypes were observed. The diagram of $\mathrm{C} 6$ allotypes identified in the present study is presented in Fig. 2. Among these allotypes six were identified as A, B, B2, B3, A21, and M91 (formerly 91), by direct comparison with Japanese control specimens (Tokunaga et al., 1983, 1984). A rare variant showed the bands slightly more acidic than those of B3, so it was designated as C6 B21 according to the International Nomenclature System (Mauff et al., 1980).

The distributions of $\mathrm{C} 6$ phenotypes and allele frequencies in two Chinese populations are presented in Table 1. The allele frequencies of $\mathrm{C} 6$ calculated from 155 individuals of Beijing population and 255 individuals of Guangzhou population were as follows: for Beijing population, $C 6^{*} A=0.4161, C 6^{*} B=0.5323, C 6^{*} B 2=$
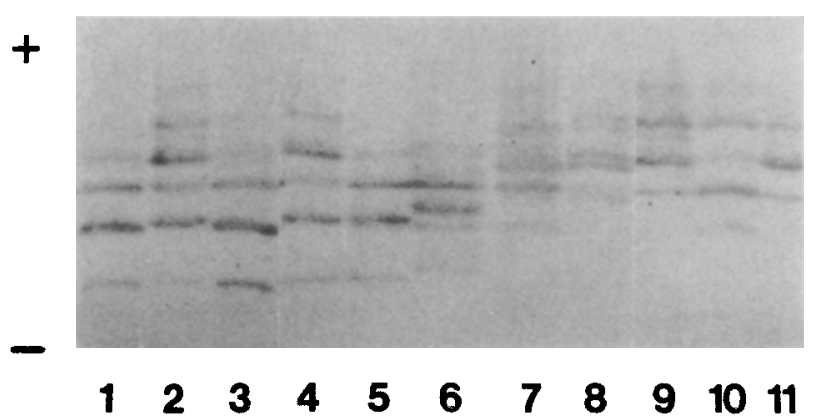

Fig. 1. Photograph showing $\mathrm{C} 6$ phenotypes demonstrated using isoelectric focusing and immunoblotting. (1) $\mathrm{C} 6 \mathrm{BB} 3$, (2) $\mathrm{C} 6 \mathrm{AB} 21$, (3) $\mathrm{C} 6 \mathrm{BB} 3$, (4) $\mathrm{C} 6 \mathrm{AB} 21$, (5) $\mathrm{C} 6$ BB21, (6) C6 BB2, (7) C6 M91B (control), (8) C6 AM91, (9) C6 A21A, (10) C6 A21B (control), (11) C6 A.

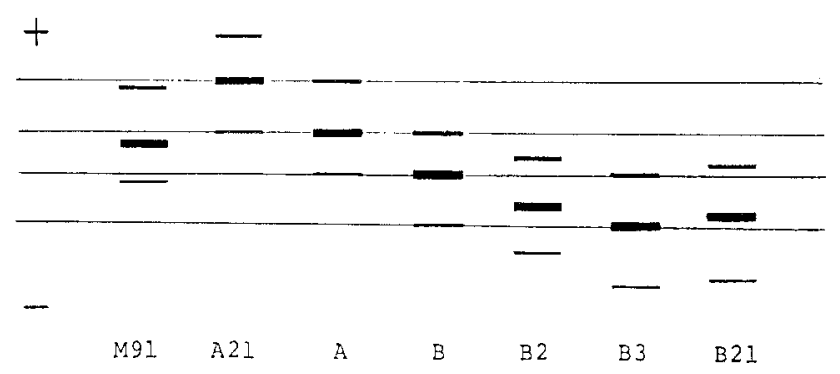

Fig. 2. Diagram of C6 allotypes identified in the present study. Only one major band, one acidic and one basic minor bands are shown for each allotype. 
Table 1. Distribution of C6 phenotype and allele frequencies.

\begin{tabular}{|c|c|c|c|c|c|}
\hline Population & Phenotypes & Obs. I & $\%$ & Exp. No. & Allele frequencies \\
\hline \multirow[t]{14}{*}{ Beijing } & A & 35 & 22.58 & 26.84 & \multirow[t]{2}{*}{$0.4161 \pm 0.0280$} \\
\hline & $\mathrm{AB}$ & 54 & 34.84 & 68.66 & \\
\hline & $\mathrm{B}$ & 50 & 32.26 & 43.92 & \multirow[t]{2}{*}{$0.5323 \pm 0.0283$} \\
\hline & $\mathrm{AB} 2$ & 3 & 1.94 & 5.40 & \\
\hline & BB2 & 10 & 6.45 & 6.91 & \multirow[t]{2}{*}{$0.0419 \pm 0.0114$} \\
\hline & $\mathrm{B} 2$ & 0 & 0 & 0.27 & \\
\hline & AR* & 2 & 1.29 & 1.25 & \multirow[t]{4}{*}{$0.0097 \pm 0.0056$} \\
\hline & $\mathrm{BR}^{*}$ & 1 & 0.64 & 1.60 & \\
\hline & $\mathrm{B} 2 \mathrm{R} *$ & 0 & 0 & 0.13 & \\
\hline & $\mathrm{R}^{*}$ & 0 & 0 & 0.01 & \\
\hline & Total & 155 & 100 & 154.99 & \multirow[t]{4}{*}{$\chi^{2}=9.9861$, d.f. $=6, p>0.10$} \\
\hline & \multirow[t]{3}{*}{ * Rare phe } & types: & AM91 1 & & \\
\hline & & & $\mathrm{A} 21 \mathrm{~A} \quad 1$ & & \\
\hline & & & BB3 1 & & \\
\hline \multirow[t]{13}{*}{ Guangzhou } & A & 54 & 21.18 & 50.52 & \multirow[t]{2}{*}{$0.4451 \pm 0.0220$} \\
\hline & $\mathrm{AB}$ & 108 & 42.35 & 117.50 & \\
\hline & B & 74 & 29.02 & 68.32 & \multirow[t]{2}{*}{$0.5176 \pm 0.0221$} \\
\hline & $\mathrm{AB} 2$ & 10 & 3.92 & 7.56 & \\
\hline & BB2 & 7 & 2.75 & 8.79 & \multirow[t]{2}{*}{$C 6^{*} B 2: \quad 0.0333 \pm 0.0079$} \\
\hline & B2 & 0 & 0 & 0.28 & \\
\hline & $A R^{*}$ & 1 & 0.39 & 0.89 & \multirow[t]{4}{*}{$0.0039 \pm 0.0028$} \\
\hline & $\mathrm{BR}^{*}$ & 1 & 0.39 & 1.03 & \\
\hline & $\mathrm{B} 2 \mathrm{R} *$ & 0 & 0 & 0.07 & \\
\hline & $\mathbf{R}^{*}$ & 0 & 0 & 0.003 & \\
\hline & Total & 255 & 100 & 254.97 & \multirow[t]{3}{*}{$\chi^{2}=2.9995$, d.f. $=6, p>0.80$} \\
\hline & \multirow{2}{*}{\multicolumn{2}{|c|}{ * Rare phenotypes: }} & $\mathrm{AB} 21 \quad 1$ & & \\
\hline & & & BB21 1 & & \\
\hline
\end{tabular}

$0.0419, C 6^{*} R=0.0097$; for Guangzhou population, $C 6^{*} A=0.4451, C 6^{*} B=0.5176$, $C 6^{*} B 2=0.0333, C 6^{*} R=0.0039$. The differences between the observed numbers and the expected numbers from Hardy-Weinberg equilibrium are not statistically significant in both populations. It was shown that there are at least three common alleles of $\mathrm{C} 6$ in Chinese as in Japanese: $C 6^{*} A, C 6^{*} B$ and $C 6^{*} B 2$.

Ten different patterns of $\mathrm{C} 7$ were observed in the present study (Fig. 3). Among these patterns, nine different $\mathrm{C} 7$ phenotypes which consisted of three homozygous 


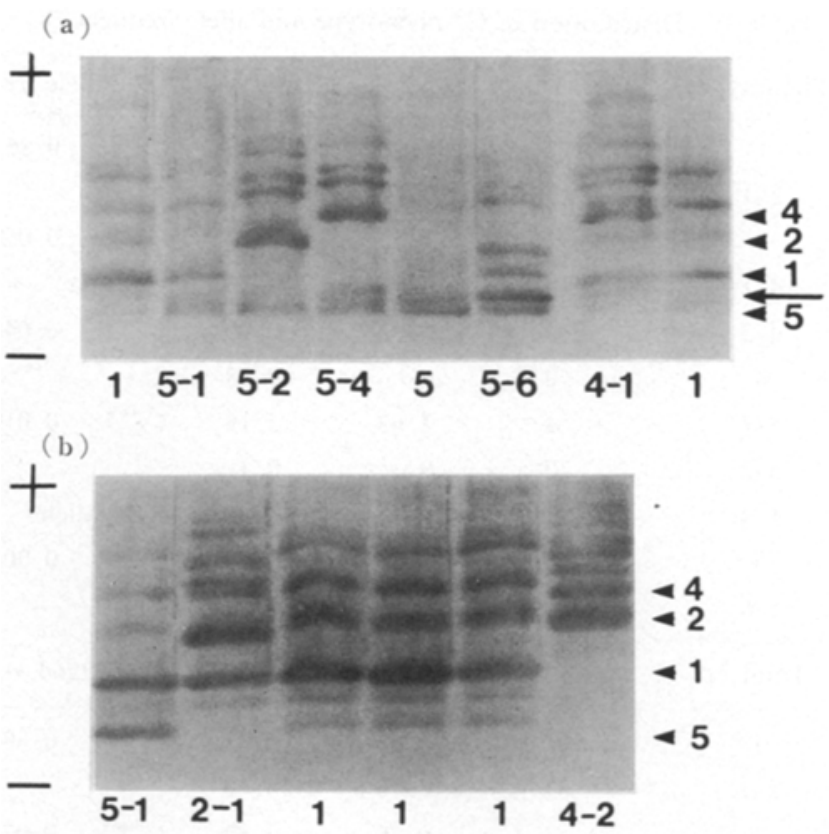

Fig. 3 (a, b). Photographs showing the different patterns of $\mathrm{C} 7$ phenotypes in the neuraminidase-treated samples, demonstrated using polyacrylamide gel isoelectric focusing immunoblotting technique.

and six heterozygous patterns were identified as C7 1, C7 2, C7 5, C7 2-1, C7 4-1, C7 4-2, C7 5-1, C7 5-2 and C7 5-4. The apparently new variant showing an intermediate band between the $\mathrm{C} 71$ and $\mathrm{C} 75$ was found once in Beijing population. It was tentatively designated as $\mathrm{C} 76$.

The distributions of the phenotypes and allele frequencies of $\mathrm{C} 7$ in the two Chinese populations are given in Table 2. The allele frequencies of $\mathrm{C} 7$ calculated from 152 individuals of Beijing population and 255 individuals of Guangzhou population were as follows: for Beijing population, $C 7^{*} 1=0.8651, C 7^{*} 2=0.0691, C 7^{*} 4=$ $0.0428, C 7 * 5=0.0197, C 7 * 6=0.0033$; for Guangzhou population, $C 7 * I=0.8843$, $C 7^{*} 2=0.0745, C 7^{*} 4=0.0098, C 7^{*} 5=0.0314$. The observed numbers of the phenotypes were in good agreement with Hardy-Weinberg expectation in both populations. It was shown that the less common alleles, $C 7^{*} 2, C 7^{*} 4$ and $C 7^{*} 5$, have polymorphic frequencies in Chinese.

Table 3 shows the result of association analysis between C6 and C7 allotypes. No significant positive association was found in Beijing and Guangzhou populations. 
Table 2. Distribution of $\mathrm{C} 7$ phenotype and allele frequencies.

\begin{tabular}{|c|c|c|c|c|c|}
\hline Population & Phenotypes & Obs. No. & $\%$ & Exp. No. & Allele frequencies \\
\hline \multirow[t]{12}{*}{ Beijing } & 1 & 117 & 76.97 & 113.76 & $C 7^{*} 1: \quad 0.8651 \pm 0.0196$ \\
\hline & $2-1$ & 15 & 9.87 & 18.18 & \\
\hline & 2 & 2 & 1.32 & 0.73 & $C 7^{*} 2: \quad 0.0691 \pm 0.0145$ \\
\hline & $4-1$ & 10 & 6.58 & 11.26 & \\
\hline & $4-2$ & 2 & 1.32 & 0.90 & $C 7^{*} 4: \quad 0.0428 \pm 0.0116$ \\
\hline & 4 & 0 & 0 & 0.28 & \\
\hline & $5-1$ & 4 & 2.63 & 5.18 & $C 7^{*} 5: \quad 0.0197 \pm 0.0080$ \\
\hline & $5-2$ & 0 & 0 & 0.41 & \\
\hline & $5-4$ & 1 & 0.66 & 0.26 & Rare allele: \\
\hline & 5 & 0 & 0 & 0.06 & $C 7^{*} 6: \quad 0.0033 \pm 0.0033$ \\
\hline & $5-6$ & 1 & 0.66 & 0.02 & \\
\hline & Total & 152 & 100.01 & 151.04 & $\chi^{2}=7.2264$, d.f. $=6, p>0.30$ \\
\hline \multirow[t]{11}{*}{ Guangzhou } & 1 & 202 & 79.22 & 199.41 & $C 7^{*} 1: \quad 0.8843 \pm 0.0142$ \\
\hline & $2-1$ & 31 & 12.16 & 33.60 & \\
\hline & 2 & 2 & 0.78 & 1.42 & $C 7^{*} 2: \quad 0.0745 \pm 0.0116$ \\
\hline & $4-1$ & 5 & 1.96 & 4.42 & \\
\hline & $4-2$ & 0 & 0 & 0.37 & $C 7^{*} 4: \quad 0.0098 \pm 0.0044$ \\
\hline & 4 & 0 & 0 & 0.02 & \\
\hline & $5-1$ & 11 & 4.31 & 14. 16 & $C 7 * 5: \quad 0.0314 \pm 0.0077$ \\
\hline & $5-2$ & 3 & 1.18 & 1.19 & \\
\hline & $5-4$ & 0 & 0 & 0.16 & \\
\hline & 5 & 1 & 0.39 & 0.25 & \\
\hline & Total & 255 & 100.00 & 255.00 & $\chi^{2}=6.8061$, d.f. $=6, p>0.30$ \\
\hline
\end{tabular}

Rare phenotype was not calculated in Chi-square.

\section{DISCUSSION}

A comparison of the $\mathrm{C} 6$ allele frequencies between Beijing and Guangzhou populations showed no statistically significant difference (Table 4).

In Table 5, the $\mathrm{C} 6$ allele frequencies in various populations thus far reported are presented. It appears that the gene frequency of $C 6^{*} B$ in Chinese is higher than that in the other populations. Interestingly, the most common allele of $\mathrm{C} 6$ in Chinese is $C 6^{*} B$, as in Japanese and Micronesian populations (Tokunaga et al., 1983, 1984; Ranford et al., 1982). In contrast, it has been shown that $C 6^{*} A$ is 
Table 3. Association analysis between $\mathrm{C} 6$ and $\mathrm{C} 7$ among unrelated Chinese.

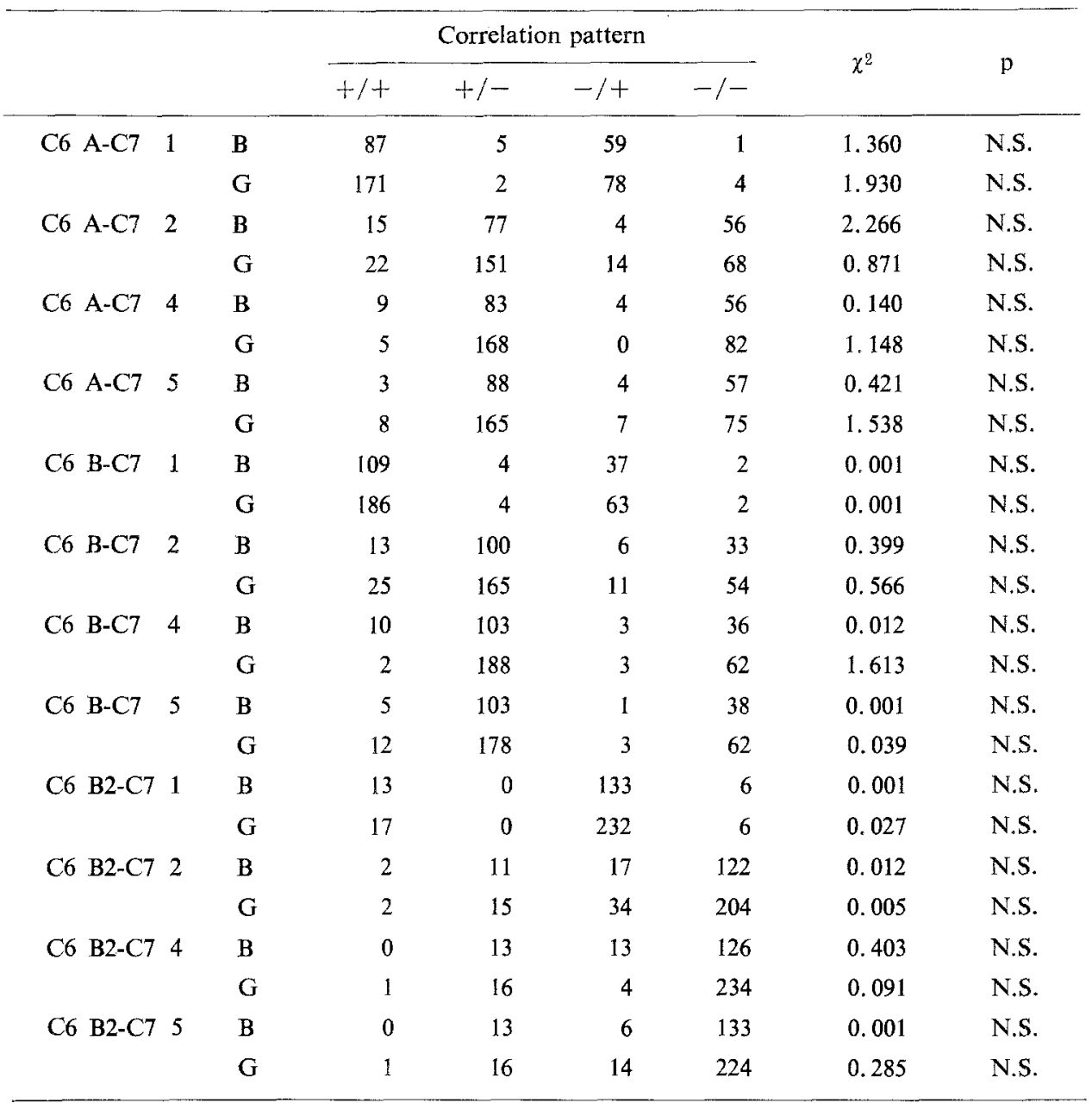

B, Beijing; G, Guangzhou; N.S., Not significant.

the most common allele in Caucasians (Hobart et al., 1976; Kunstmann et al., 1980; Olving et al., 1980).

The gene frequency of $C 6^{*} B 2$ in Chinese, is a little lower than those in Japanese and in Micronesian but higher than those in the other populations, especially, in Caucasians. The allele $C 6^{*} B 3$ was suggested to be the fourth common allele in a western Japanese population (Nishimukai et al., 1985). Nevertheless, it seems to be rare in Chinese populations as in eastern Japanese (Tokunaga et al., 1983, 1984; Nakamura et al., 1984b).

A comparison of the $\mathrm{C} 7$ allele frequencies (Table 4 ) indicated that there are no 
Table 4. Comparisons of $\mathrm{C} 6$ and $\mathrm{C} 7$ allele frequencies between two Chinese populations.

\begin{tabular}{lccccc}
\hline Population & $\mathrm{N}$ & $C 6^{*} A$ & $C 6^{*} B$ & $C 6^{*} B 2$ & Others \\
\hline Beijing & 155 & 0.4161 & 0.5323 & 0.0419 & 0.0097 \\
Guangzhou & 255 & 0.4451 & 0.5176 & 0.0333 & 0.0039 \\
& & $\chi^{2}=0.660$ & $\chi^{2}=0.167$ & $\chi^{2}=0.405$ & $\chi^{2}=1.070$ \\
& & $\mathrm{~d} . \mathrm{f}=1$ & $\mathrm{~d} . \mathrm{f}=1$ & d.f. $=1$ & $\mathrm{~d} . \mathrm{f}=1$ \\
& $\mathrm{p}>0.30$ & $\mathrm{p}>0.50$ & $\mathrm{p}>0.50$ & $\mathrm{p}>0.30$ \\
\hline Beijing & $\mathrm{N}$ & $C 7^{*} 1$ & $C 7^{*} 2$ & $C 7^{*} 4$ & $C 7^{*} 5$ \\
Guangzhou & 152 & 0.8651 & 0.0691 & 0.0428 & 0.0197 \\
& 255 & 0.8843 & 0.0745 & 0.0098 & 0.0314 \\
& & $\chi^{2}=0.651$ & $\chi^{2}=0.082$ & $\chi^{2}=9.606$ & $\chi^{2}=0.992$ \\
& & d.f. $=1$ & d.f. $=1$ & d.f. $=1$ & d.f. $=1$ \\
& & $\mathrm{p}>0.30$ & $\mathrm{p}>0.70$ & $\mathrm{p}<0.005$ & $\mathrm{p}>0.30$ \\
\hline
\end{tabular}

Table 5. C6 allele frequencies in various populations.

\begin{tabular}{|c|c|c|c|c|c|c|}
\hline \multirow{2}{*}{ Population } & \multirow{2}{*}{ No. } & \multicolumn{4}{|c|}{ C6 allele } & \multirow{2}{*}{ Authors } \\
\hline & & A & B & $\mathrm{B} 2$ & Others & \\
\hline \multicolumn{7}{|l|}{ China } \\
\hline Beijing & 155 & .416 & .532 & .042 & .010 & Present study \\
\hline Guangzhou & 255 & .445 & .518 & .033 & .004 & \\
\hline Japan & $135-495$ & $.423-.467$ & $.481-.510$ & $.037-.076$ & $.005-.015$ & $\begin{array}{l}\text { Tokunaga et al., } \\
\text { 1983, 1984; } \\
\text { Nishimukai et al., } 1985\end{array}$ \\
\hline \multicolumn{7}{|l|}{ W. Pacific } \\
\hline Micronesia & 186 & .446 & .452 & .067 & .035 & Ranford et al., 1982 \\
\hline Polynesia & 245 & .629 & .359 & .006 & .006 & \\
\hline Melanesia & 186 & .693 & .307 & .000 & .000 & \\
\hline Germany & 709 & .601 & .388 & .003 & .008 & Kunstmann et al., 1980 \\
\hline \multicolumn{7}{|l|}{ Norway } \\
\hline Lapps & 167 & .533 & .467 & .000 & .000 & Olving et al., 1980 \\
\hline Caucasian & 1623 & .587 & .409 & .0 & & Olving et al., 1980 \\
\hline
\end{tabular}

statistically significant differences for the allele frequencies of $C 7 * 1, C 7 * 2$ and $C 7 * 5$ between Beijing and Guangzhou populations, while for the allele frequency of $C 7^{*} 4$, there is highly significant difference between the two populations $(\mathrm{p}<0.005)$. The result suggests that this allele has a geographically restricted distribution in the 
northern Chinese population and spread to the southern Chinese population by gene flow. It is interesting to examine other Chinese populations in this respect.

Nakamura and his colleagues described a result of an association analysis between $\mathrm{C} 6$ and $\mathrm{C} 7$ in a Japanese population. They suggested that two combinations between $\mathrm{C} 6$ and $\mathrm{C} 7$ alleles are in positive linkage disequilibrium (Nakamura et al., 1984b). However, Tokunaga et al. (1986) found no evidence of linkage disequilibrium between $\mathrm{C} 6$ and $\mathrm{C} 7$ alleles in a haplotype study with 135 genotyped families. Nishimukai and Tamaki (1986) also found no significant association in a Japanese population. In this study, again no association between $\mathrm{C} 6$ and $\mathrm{C} 7$ alleles was found.

Note Added in Proof: Recently, the correspondence of the C7 5 (Nishimukai and Tamaki, 1986) with the C7 3 reported by Hobart et al. (1978) has been confirmed (see Washio et al., Jpn J. Human Genet. in press).

\section{REFERENCES}

Hobart, M.J., Lachmann, P.J., and Alper, C.A. 1975. Polymorphism of human C6. In Protides of the Biological Fluids, Peeters, H. ed., 22nd Colloq., Pergamon Press, Oxford, pp. 575-580.

Hobart, M.J., Joysey, V., and Lachmann, P.J. 1978. Inherited structural variation and linkage relationships of C7. J. Immunogenet. 55: 157-163.

Kunsmann, G., Mauff, G., and Pulverer, G. 1980. C6 polymorphism and rare alleles in Western Germany. Immunobiology 158: 55-59.

Mauff, G., Alper, C.A., Hobart, M.J., Kühnl, P., Kunstmann, G., Meo, T., Olving, J.H., and Rittner, C.H. 1980. Statement on the nomenclature of human C6 polymorphism. Immunobiology 158: 139-143.

Nakamura, S., Ooue, O., and Abe, K. 1984a. Genetic polymorphism of the seventh component of complement in a Japanese population. Hum. Genet. 66: 279-281.

Nakamura, S., Ooue, O., Akiyama, K., and Abe, K. 1984b. Genetic polymorphism of complement C6 and haplotype analysis between $\mathrm{C} 6$ and $\mathrm{C} 7$ in a Japanese population. Hum. Genet. 68: $138-141$.

Nishimukai, H., Kitamura, H., Kishida, T., and Tamaki, Y. 1985. C6 polymorphism in Japanese: Typing by agarose gel isoelectric focusing-immunofixation. Hum. Hered. 35: 30-33.

Nishimukai, H. and Tamaki, Y. 1986. Genetic polymorphism of the seventh component of complement: A new variant. Vox Sang. 51: 60-62.

Olving, J.H., Teisberg, P., and Olaisen, B. 1980. Polymorphism of the sixth component of complement (C6) in Norwegian Lapps. Hum. Hered. 30: 211-214.

Ranford, P.R., Kirk, R.L., and Zimmet, P. 1982. Distribution of complement factors BF, C2 and C6 in the Western Pacific. Acta Anthropogenetica 6: 23-32.

Tokunaga, K., Yukiyama, Y., and Omoto, K. 1983. Polymorphism of the complement component C6 in Japanese. J. Immunogenet. $10: 419-424$.

Tokunaga, K., Yamamura, N., and Omoto, K. 1984. An immunoblotting technique for complement C6 typing: Three new variants. Jpn. J. Human Genet. 29: 415-419.

Tokunaga, K., Dewald, G., Omoto, K., and Juji, T. 1986. Family study on the polymorphisms of the sixth and seventh components ( $\mathrm{C} 6$ and $\mathrm{C} 7$ ) of human complement: Linkage and haplotype analyses. Am. J. Hum. Genet. 39: 414-419. 